\title{
OPEN
}
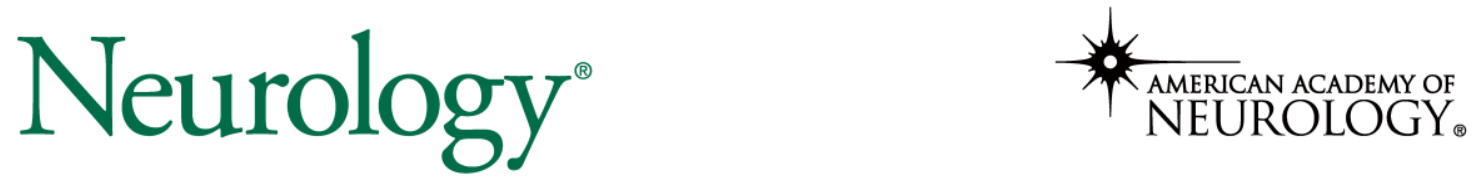

The most widely read and highly cited peer-reviewed neurology journal

The Official Journal of the American Academy of Neurology

Neurology Publish Ahead of Print

DOI: 10.1212/WNL.0000000000200046

\section{Associations of Stages of Objective Memory Impairment (SOMI) with Amyloid PET and Structural MRI: The A4 Study.}

\section{Author(s):}

Ellen Grober, $\mathrm{PhD}^{1}$; Richard B Lipton, $\mathrm{MD}^{1}$; Reisa A Sperling, MD ${ }^{2,3}$; Kathryn V Papp, PhD ${ }^{2,3}$; Keith A Johnson, $\mathrm{MD}^{2,3}$; Dorene M Rentz, $\mathrm{PhD}^{2,3}$; Amy E Veroff, PhD ${ }^{1}$; Paul S Aisen, MD ${ }^{4}$; Ali Ezzati, MD ${ }^{1}$

\section{Corresponding Author:}

Ellen Grober

ellen.grober@einsteinmed.org

This is an open access article distributed under the terms of the Creative Commons Attribution-NonCommercial-NoDerivatives License 4.0 (CC BY-NC-ND), which permits downloading and sharing the work provided it is properly cited. The work cannot be changed in any way or used commercially without permission from the journal.

Neurology® Published Ahead of Print articles have been peer reviewed and accepted for publication. This manuscript will be published in its final form after copyediting, page composition, and review of proofs. Errors that could affect the content may be corrected during these processes. 
Affiliation Information for All Authors: 1. Department of Neurology, Albert Einstein College of Medicine, Bronx, NY 2. Harvard Aging Brain Study, Department of Neurology,Massachusetts General Hospital, Harvard Medical School, Boston, MA 3.Center for Alzheimer Research and Treatment, Department of Neurology, Brigham and Women's Hospital, Boston, MA 4. Alzheimer's Therapeutic Research Institute, University of Southern California, San Diego, CA

\section{Contributions:}

Ellen Grober: Drafting/revision of the manuscript for content, including medical writing for content; Study concept or design; Analysis or interpretation of data

Richard B Lipton: Drafting/revision of the manuscript for content, including medical writing for content; Analysis or interpretation of data

Reisa A Sperling: Drafting/revision of the manuscript for content, including medical writing for content; Major role in the acquisition of data

Kathryn V Papp: Drafting/revision of the manuscript for content, including medical writing for content; Major role in the acquisition of data

Keith A Johnson: Major role in the acquisition of data

Dorene M Rentz: Drafting/revision of the manuscript for content, including medical writing for content; Major role in the acquisition of data

Amy E Veroff: Drafting/revision of the manuscript for content, including medical writing for content Paul S Aisen: Major role in the acquisition of data

Ali Ezzati: Drafting/revision of the manuscript for content, including medical writing for content; Study concept or design; Analysis or interpretation of data

Figures: 2

Tables: 3

\section{Clinical Trial registration number: NCT02008357}

Search Terms: [ 26 ] Alzheimer's disease, [ 120 ] MRI, [ 122 ] PET, [ 201 ] Memory

Acknowledgements: The A4 Study is a secondary prevention trial in preclinical Alzheimer's disease, aiming to slow cognitive decline associated with brain amyloid accumulation in clinically normal older individuals. The A4 Study is funded by a public-private-philanthropic partnership, including funding from the National Institutes of Health-National Institute on Aging, Eli Lilly and Company, Alzheimer's Association, Accelerating Medicines Partnership, GHR Foundation, an anonymous foundation and additional private donors, with in-kind support from Avid and Cogstate. The companion observational Longitudinal Evaluation of Amyloid Risk and Neurodegeneration (LEARN) Study is funded by the Alzheimer's Association and GHR Foundation. The A4 and LEARN Studies are led by Dr. Reisa Sperling at Brigham and Women's Hospital, Harvard Medical School and Dr. Paul Aisen at the Alzheimer's Therapeutic Research Institute (ATRI), University of Southern California. The A4 and LEARN Studies are coordinated by ATRI at the University of Southern California, and the data are made available through the Laboratory for Neuro Imaging at the University of Southern California. The participants screening for the A4 Study provided permission to share their de-identified data in order to advance the quest to find a successful treatment for Alzheimer's disease. We would like to acknowledge the dedication of all the participants, the site personnel, and all of the partnership team members who continue to make the A4 and LEARN Studies possible. The complete A4 Study Team list is available on: a4study.org/a4study-team.

Study Funding: R.B.L receives research support from the following sources unrelated to this manuscript: 5U10 NS077308 (PI), R21 AG056920 (Investigator), 1RF1 AG057531 (Site PI), RF1 AG054548 (Investigator), 1RO1 AG048642 (Investigator), R56 AG057548 (Investigator), U01062370 (Investigator), RO1 AG060933 (Investigator), RO1 AG062622 (Investigator), 1UG3FD006795 (mPI), 1U24NS113847 (Investigator). R.A.S. receives research support from National Institute on Aging: P01 AG036694; R01 AG054029; R01 AG063689; R01AG053798; U24AG057437; K24 AG035007, Alzheimer's Association: LEARN-15-338729, and clinical trial research support from Eli Lilly and Co. and Eisai. P.S.A receives 
research support from the National Institute on Aging, the Alzheimer's Association and the Foundation for $\mathrm{NIH}$, and has research agreements with Lilly and Eisai. A.E. receives research support from NIA K23 AG063993, A.E.; 2PO1 AG003949, the Alzheimer's Association (2019-AACSF-641329), Cure Alzheimer Fund.

Disclosures: E.Grober receives a small royalty for commercial use of the Free and Cued Selective Reminding Test with Immediate Recall (FCSRT+IR; R.B.Lipton receives research support from the following sources unrelated to this manuscript: 5U10 NS077308 (PI), R21 AG056920 (Investigator), 1RF1 AG057531 (Site PI), RF1 AG054548 (Investigator), 1RO1 AG048642 (Investigator), R56 AG057548 (Investigator), U01062370 (Investigator), RO1 AG060933 (Investigator), RO1 AG062622 (Investigator), 1UG3FD006795 (mPI), 1U24NS113847 (Investigator). He holds stock options in eNeura Therapeutics and Biohaven Holdings, serves as consultant, advisory board member, or has received honoraria from: Abbvie (Allergan), American Academy of Neurology, American Headache Society, Amgen, Avanir, Biohaven, Biovision, Boston Scientific, Dr. Reddy's (Promius), Electrocore, Eli Lilly, eNeura Therapeutics, Equinox, GlaxoSmithKline, Grifols, Lundbeck (Alder), Merck, Pernix, Pfizer, Supernus, Teva, Trigemina, Vector, Vedanta, receives royalties from Wolff's Headache 7th and 8th Edition, Oxford Press University, 2009, Wiley and Informa; R.A.Sperling receives research support from National Institute on Aging: P01 AG036694; R01 AG054029; R01 AG063689; R01AG053798; U24AG057437; K24 AG035007, Alzheimer's Association: LEARN-15-338729, and clinical trial research support from Eli Lilly and Co. and Eisai, has received consulting fees from AC Immune, Acumen, Genentech, Janssen, Cytox, Prothena, Renew, Alnylam, Neuraly, and Neurocentria; P.S.Aisen receives research support from the National Institute on Aging, the Alzheimer's Association and the Foundation for NIH, and has research agreements with Lilly and Eisai, receives consulting fees from Merck, Biogen, Abbvie, Roche, Rainbow Medical, Immunobrain Checkpoint and Shionogi; A.E.Veroff receives consulting fees from Janssen and a small royalty for commercial use of some FCSRT materials; A.Ezzati serves as consultant, advisory board member, and has received honoraria from Eisai, and PCORI Health Care Horizon Scanning Team; K.V.Papp has received funding from the Alzheimer's Association and the National Institute of Health, has served a paid consultant for Biogen Idec and Digital Cognition Technologies;

D.M.Rentz receives consulting and scientific advisory board fees from Digital Cognition Technologies, Biogen Idec and Neurotrack; K.A.Johnson receives research support from National Institute on Aging: P01 AG036694, R01 AG054029, R01 AG063689; R01AG053798, U24AG057437, R01AG054076, R01AG049607, National Institute on Deafness and Other Communication Disorders, R01DC014296; Alzheimer's Association, LEARN-15-338729, clinical trial research support from Eli Lilly and Co., Cerveau, and Eisai and received consulting fees from AC Immune, AZTherapies, Genentech, Janssen, Takeda, and Novartis.

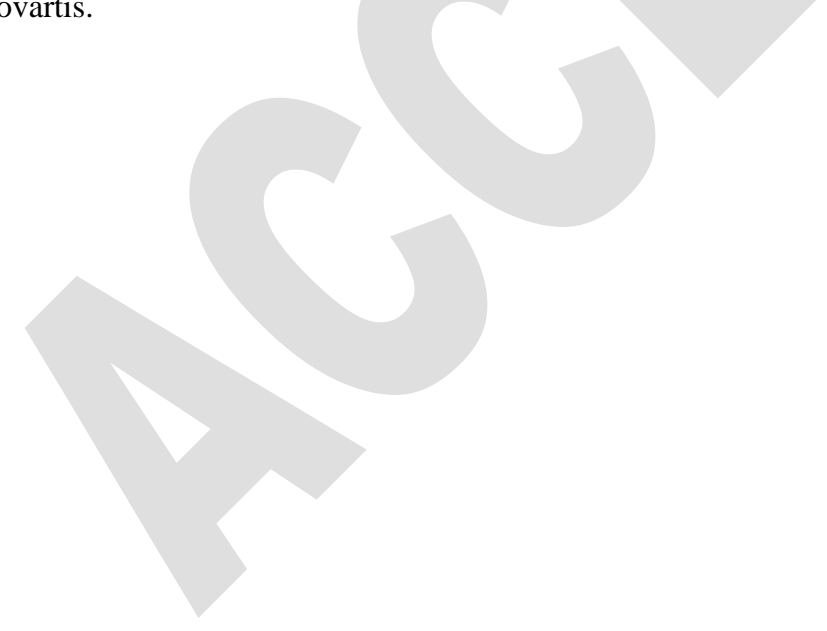




\section{ABSTRACT}

\section{Objective}

To investigate the neuroimaging correlates of the Stages of Objective Memory Impairment (SOMI) system operationalized using Free and Cued Selective Reminding Test (FCSRT), a widely used episodic memory measure.

\section{METHODS}

The FCSRT begins with a study phase in which items (e.g., grapes) are identified in response to unique semantic cues (e.g., fruit) that are used in the test phase to prompt recall of items not retrieved by free recall $(F R)$. There are 3 test trials of the 16 items (max=48). Data from 4484 cognitively unimpaired participants from the Anti-Amyloid Treatment in Asymptomatic Alzheimer's (A4) study were used. All participants had amyloid PET imaging and a subset of $1262 \beta$-amyloid $(A \beta) A \beta+$ had structural MRIs. We compared the $A \beta$ mean cortical standardized uptake value ratio (SUVR) and volumetric measures of hippocampus, parahippocampal gyrus, entorhinal cortex, and inferior temporal cortex between the five SOMI stages.

\section{RESULTS}

Participants had a mean age of $71.3(\mathrm{SD}=4.6)$ years, were $40.6 \%$ male, and $34.6 \%$ were APOE4 positive. Half had no memory impairment; the other half had retrieval deficits, storage limitations or both. Analysis of covariance in the entire sample while controlling for age, sex, education, and APOE4, showed that individuals in higher SOMI 
stages had higher global amyloid SUVR ( $p<.001)$. Both SOMI-4 and SOMI-3 subgroups had higher amyloid SUVR than SOMI-0 and SOMI-1 subgroups. Higher SOMI stages had smaller hippocampal volume $(p=.003)$, entorhinal cortex $(p<.05)$, and inferior temporal lobes $(p<.05)$, but there was no difference between parahippocampal gyrus volume of different SOMI stages. Pairwise comparison of SOMI subgroups showed that SOMI-4, 3, and 2 had smaller hippocampal volume in comparison with SOMI-0, and SOMI-1. SOMI-4 had significantly smaller entorhinal cortex and smaller inferior temporal lobe in comparison with all other groups.

\section{DISCUSSION}

Presence of AD-pathology is closely related to memory impairment based on SOMI stages in the cognitively unimpaired sample of A4. Results from structural MRIs suggest that memory storage impairment (SOMI-3 and SOMI-4) is present when there is widespread medial temporal lobe atrophy.

\section{CLASSIFICATION OF EVIDENCE}

This study provides Class I evidence that, in normal elderly, higher stages of memory impairment assessed using FCSRT were associated with higher amyloid imaging burden and lower volume of hippocampus, entorhinal cortex and inferior temporal lobes. 


\section{INTRODUCTION}

Performance on the Free and Cued Selective Reminding (FCSRT) defines what is sometimes called the "core clinical phenotype of Alzheimer's disease (AD)", a memory disorder that cannot be remediated by effective encoding and retrieval processes. ${ }^{1,2}$ This phenotype is also called the "amnestic syndrome of the hippocampal type" based on its association with structural changes in medial temporal lobe (MTL), especially in the hippocampus and its subfields. ${ }^{3}$ Many studies have reported strong associations among AD-biomarkers, including neuroimaging and CSF biomarkers of amyloid, tau, and neurodegeneration, and the two main FCSRT measures: free recall (FR) and total recall (TR), the sum of FR and cued recall. ${ }^{4-11}$

The effectiveness of FCSRT in identifying prevalent dementia, predicting incident $\mathrm{MCl}$, dementia, and $A D$, and in distinguishing between $A D$ and non- $A D$ dementias in various longitudinal aging cohorts ${ }^{12-18}$ is because the test controls the conditions of learning. In the study phase, participants are asked to identify items (e.g., grapes) in response to unique semantic cues (fruit); these cues are used in the test phase to prompt recall of items not retrieved by FR. ${ }^{19}$ In contrast to passively listening as items are presented in conventional word list learning tests, the FCSRT requires active cognitive engagement and deep semantic processing. By coordinating the conditions of encoding and retrieval with category cues, the FCSRT optimizes encoding specificity and maximizes recall. ${ }^{20}$

While impaired FR has predicted incident $A D$ in several longitudinal aging cohorts, $12,15,21,22$ it is not optimized to identify $A \beta$ status in cognitively normal individuals. ${ }^{23}$ To 
overcome this limitation and identify participants at an earlier point in the preclinical AD trajectory, we developed the Stages of Objective Memory Impairment (SOMI) system, which provides practical cut-offs for classification of participants into one of five stages by both FR and TR scores (Table 1). ${ }^{24}$ Using Einstein Agng Study (EAS) data, we investigated if the SOMI system is effective in identifying individuals at higher risk of incident $A D$. We showed that the first three SOMI stages (SOMI 0-2) typically precede clinical dementia by 5 to 8 years and reflect increasing retrieval difficulty, shown by declining FR in the context of intact TR. The next two SOMI stages (SOMI 3, 4) precede clinical dementia by about 1 to 3 years; in these stages cuing fails to recover all of the items missed on FR. SOMl's advantage over individual FR and TR scores is that it separates the measurement of retrieval impairment from memory storage impairment. Since these processes' breakdown at different points in the predementia phase, the ability to distinguish between them allows an estimate of the participant's stage of illness along the AD continuum.

We have recently shown that participants whose pFCSRT+IR performance classified them as SOMI-2 (moderate retrieval impairment) were at higher risk of incident AD (personal communication). Out of 1508 participants from the Baltimore Longitudinal Aging Study who were free of dementia at baseline, 85 individuals developed AD over an average of more than 8 years of follow-up. Using Bayesian joint modeling and all observed assessments, the diagnostic accuracy of SOMI (82\%) was superior to FR alone $(74 \%)$ or the sum of FR+TR $(71 \%)$ in identifying incident $A D$ after 3,5 and 7 years of follow-up, demonstrating SOMl's advantage over individual FR and TR scores. 
The SOMI system could be useful for screening in clinical trials, if performance was associated with the ante-mortem biomarkers of amyloid, tau, and neurodegeneration used in the NIA-AA Research Framework. ${ }^{25}$ Since the pFCSRT+IR is currently used in the Anti-Amyloid Treatment in Asymptomatic Alzheimer's (A4) study ${ }^{26}$ and prerandomization data are publicly available, we were able to classify participants into SOMI stages. This allowed us to examine SOMl's association with PET amyloid imaging and neurodegeneration using volumetric MRI. We predicted that participants in higher stages (SOMI-3,4) will have both higher global amyloid deposition and greater atrophy of hippocampal subregions than participants with no or mild impairment (SOMI$0,1)$.

\section{METHODS}

\section{Participants.}

A4 is a multicenter clinical trial being conducted in the US, Canada, Australia, and Japan. Details for screening process are described previously. ${ }^{22}$ In brief, participants eligible for screening were age 65 to 85 years, assessed to be cognitively normal (CN), living independently, and had a study partner who would be able to provide information on daily life cognitive function on an annual basis. Participants with very low ( $\leq 1.5 \mathrm{SD}$ below norms) Logical Memory Delayed Recall (LMDR-Ila) scores were excluded to eliminate individuals with mild cognitive impairment. Participant with very high ( $>1.5 \mathrm{SD}$ above norms) LMDR-lla scores were excluded after screening visit 1 to enhance enrollment of participants at higher risk of imminent cognitive decline associated with 
AD pathology. Participants with a Clinical Dementia Rating score of 0, Mini-Mental State Examination (MMSE) score of 25 to 30 , and LMDR-Ila score of 6 to 18 were eligible to proceed to florbetapir PET imaging.

\section{FCSRT.}

In the study phase of picture version of the FCSRT that includes immediate recall (pFCSRT+IR) participants were asked to search a card containing four line drawings (e.g., grapes) for an item that goes with a unique category cue (e.g., fruit). A stimulus card is included in the supplemental material (eFigure 1). After all four items were identified, immediate cued recall of just those four items was tested. The study phase was repeated for all 16 drawings. The test phase consisted of three trials of free recall each followed by cued recall for items not retrieved by free recall (maximum score $=$ 48). Participants were stratified into different SOMI subgroups using the score ranges of FR and TR (sum of FR and cued recall) as shown in Table 1.

\section{Amyloid PET Imaging}

At screening participants underwent amyloid PET imaging, acquired using florbetapir $F$ 18 and measured using a mean cortical standardized uptake value ratio (SUVr) with a whole cerebellar reference region. ${ }^{27}$ We used a quantitative SUVR threshold of 1.10 or more to define amyloid positivity $(A \beta+) .{ }^{28}$ 


\section{Volumetric MRI}

Only a subset of participants who were amyloid positive underwent structural MRI at baseline visit. Therefore, volumetric MRI measures were available for $1262 \mathrm{~A} \beta+$ participants. Volumetric measures of different cortical and subcortical regions were calculated automatically for all participants using FreeSurfer $6.0 .^{29}$ For the purpose of this study, volumetric measures were collapsed across hemispheres and adjusted for estimated total intracranial volume.

\section{Statistical analyses.}

Statistical analyses were completed with SPSS version 25 and Python version 3.9. Sample characteristic differences among SOMI groups were examined with $x^{2}$ tests for categorical variables and analyses of variance for continuous variables (2-sided, $p<0.05)$. We used analysis of covariance (ANCOVA) to compare biomarker values of SOMI groups accounting for age, sex, education, and APOE4 status. Post-hoc pairwise comparisons with Sidak correction were performed to assess differences between groups defined by SOMI and $p$-values of $>0.005$ were considered significant $(\alpha=0.05,10$ group comparisons).

\section{Data Availability}

Anonymized data is publicly available to any qualified investigator through LONI website at: https://ida.loni.usc.edu/login.jsp?project=ADNI.

\section{RESULTS}




\section{Sample Characteristic.}

A total of 4484 cognitively unimpaired adults were included in this study, and volumetric MRI was available for $1262 \mathrm{~A} \beta+$ participants. Participants had a mean age of 71.3 $(\mathrm{SD}=4.6)$ years, were $40.6 \%$ male, had 16.6 years of education, and $34.6 \%$ were ApOE4 positive. The mean FR was 29.0 ( $S D=5.59)$ and TR was $47.4(\mathrm{SD}=0.9)$.

Table 2 summarizes sample characteristics and classification of participants into SOMI stages. Participants in higher SOMI stages were older in age $(F=44.7, p<.001)$ and more likely to be female $(F=54.0, p<.001)$. SOMI groups did not differ in education or relative frequency of ApOE4 status. A total of $162(3.6 \%)$ individuals could not be classified by the SOMI system because retrieval was impaired, but storage was unimpaired. In comparison with A $\beta$ - individuals classified as SOMI-0 or SOMI-1, those categorized as SOMI-3 or SOMI-4 were older ( $\mathrm{p}<0.001$ for all comparisons), more likely to be female $(p<0.001$ for all), but they did not differ on education. Table 3 summarized the characteristics of $A \beta$ - and $A \beta+$ individuals according to SOMI stages.

\section{Differences in Amyloid levels}

Analysis of covariance in the entire sample showed that individuals in higher SOMI stages, had higher global amyloid SUVR $(F=8.4, p<.001)$. Specifically, SOMI-4 had higher amyloid SUVR than SOMI-1 $(p<.001)$. SOMI-3 had higher amyloid SUVR than SOMI-0 $(p<.001)$ and SOMI-1 $(p=0.003)$. There was no difference between amyloid SUVR of SOMI-0, 1, or 2 (Figure 1a). We stratified the sample into $A \beta$ - and $A \beta+$ 
subgroups, to evaluate subthreshold and suprathreshold amyloid SUVR differences between the SOMI stages. At subthreshold levels (A $\beta$-), amyloid SUVR was not significantly different between SOMI stages. At suprathreshold levels $(A \beta+)$, SOMI-4 had higher but not significant (after correction for multiple comparison) amyloid SUVR than SOMI-0 $(p=.008)$, SOMI-1 $(p=.009)$, and SOMI $3(p=.039)$ (Figure 1b).

\section{Differences in volumetric MRI measures}

Univariate analysis accounting for age, gender, education, and APOE4, showed that higher SOMI stages had smaller hippocampal volume ( $F=3.66, p=.003)$ (Figure 2). Pairwise comparison showed that SOMI-0 had the largest hippocampal volume in comparison with all other groups (SOMI-1, $\mathrm{p}=.002$; SOMI-2, 3, and $4 \mathrm{p}<.001$ for all). SOMI-1 also had larger hippocampal volume than SOMI-2 ( $p=.015)$, SOMI-3 $(p<.001)$, and SOMI-4 $(p<.001)$. There was no difference between hippocampal volume of SOMI2 and SOMI-3 $(\mathrm{p}=.202)$ or SOMI-2 and SOMI-4 $(\mathrm{p}=.026)$ or SOMI-3 and SOMI-4 $(p=.102)$. Addition of amyloid SUVR to the univariate analysis as a covariate, attenuated the differences, however the difference between SOMI subgroups remained significant $(F=3.24, p=.007)$.

There was no significant difference between parahippocampal gyrus volume between SOMI subgroups higher SOMI stages had smaller entorhinal cortex $(F=2.25, p=.047)$, and inferior temporal lobes $(\mathrm{F}=2.39, \mathrm{p}=.036)$. Post-hoc analysis showed that SOMI-4 had smaller entorhinal cortex than SOMI-1 $(p=.002)$, and SOMI- $(p=.005)$, but there was no difference between entorhinal cortex volume among other subgroups. In addition, post-hoc analysis showed that SOMI-3 had smaller inferior temporal lobes than SOMI-0 $(p<.001)$ and SOMI-1 $(p=.004)$. Addition of amyloid SUVR to the univariate 
analysis as a covariate, did not affect significant differences observed between subgroups.

\section{Classification of Evidence}

This study provides Class I evidence that, in normal elderly, higher stages of memory impairment assessed using FCSRT were associated with higher amyloid imaging burden and lower volume of hippocampus, entorhinal cortex and inferior temporal lobes.

\section{DISCUSSION}

The SOMI system distinguishes retrieval impairment observed in preclinical $A D$ in the context of intact memory storage from memory storage impairment that occurs later in the AD continuum. We used FR and TR scores on pFCSRT+IR to classify participants from the A4 study into SOMI stages. The sample was screened to have a Clinical Dementia Rating global score of 0, a Mini-Mental State Examination (MMSE) score of 25 to 30 , and LMDR-Ila score of 6 to 18 . Even in this sample, extensively screened to identify and eliminate participants with cognitive impairment, including memory impairment based on delayed story recall, 511 of 4484 (11.4\%) were SOMI 3/4, indicating that they had both memory retrieval and storage impairment based on the FCSRT. This indicates that the FCSRT detects memory impairment in an ostensibly cognitively normal group. 
We examined the association of SOMI stage with global amyloid levels. In the entire cohort, as SOMI stage increased the proportion of participants who were $A \beta+$ also increased. Among $A \beta+$ individuals those in higher SOMI stages had higher global amyloid levels. Individuals in SOMI stages 3 and 4 (those with storage and retrieval deficits) had significantly higher amyloid levels compared to individuals in earlier SOMI stages (those with unimpaired memory or mildly impaired retrieval). These findings suggest that memory impaired individuals detected by SOMI in this "cognitively normal" group have a biological substrate for cognitive impairment; higher levels of amyloid are associated with concurrent storage and retrieval deficits.

The relationship between SOMI stage and atrophy of MTL subregions complements SOMl's relationship with global amyloid levels. Only $A \beta+$ individuals underwent structural MRI at baseline, providing volumetric measures of the hippocampus, parahippocampal gyrus, entorhinal cortex, and inferior temporal cortex. The relationship of volumetric measure to SOMI stage differed among measures: 1) progressing from one SOMI stage to the next was associated with increasing levels of hippocampal atrophy; 2) individuals with impairment of memory storage (SOMI-3 and 4) displayed greater atrophy of the inferior temporal cortex compared to those with no storage impairment; and 3) atrophy of the entorhinal cortex was only present in SOMI-4 compared to all other stages which did not differ.

Our results indicate that even among individuals screened for cognitive impairment, hippocampal atrophy is evident in $A \beta+$ subgroups with retrieval but not storage 
impairment. Prior studies suggest that hippocampal volume atrophy might be the earliest sign of neurodegeneration due to $A D{ }^{30,31}$ The development of memory storage impairment was associated with atrophy of inferior temporal cortex but volume loss in entorhinal cortex occurred only with advanced storage issues in SOMI-4.

We expect that the relationship between SOMI stage and MRI volumetrics would likely be weaker in a sample not screened for amyloid positivity. This is a limitation on generalizability of our results imposed by the design of A4 study. Volumetric data is currently available only for the amyloid positive individuals in the A4 study, but a parallel study (LEARN cohort) is following a smaller sample $(\mathrm{N}=600)$ of amyloid negative individuals from A4 study, and we are hoping to conduct a follow up study using data from that sample.

SOMI stages displayed a similar relationship to hippocampal volume and tau PET imaging of the entorhinal and inferior temporal cortices among participants in the Harvard Aging Brain Study. ${ }^{32}$ Mean hippocampal volume for individuals in SOMI stages 3 and 4 combined was smaller than for individuals in SOMI stages 0,1 , and 2. Mean inferior temporal tau in SOMI-3/4 stages was higher in comparison to SOMI-0 and 1 and mean entorhinal tau in SOMI-3/4 was higher in comparison with SOMI-0. Together, these results indicate that memory storage impairment is present when there is widespread medial temporal lobe pathology. 
In this study, the base rate of amyloid positivity among all participants was $32 \%$. Rates of amyloid positivity were $30 \%$ for Stage $0,31 \%$ for Stage 1, 35\% for Stage 2, 40\% for Stage 3 , and $44 \%$ for stage 4 . A sensitivity analysis indicated that the SOMI system can add incremental value to using a single FR and TR cut-off for identifying amyloid positives. The optimal Youden index-based cut-off point for prediction of $A \beta$ positivity for FR was $30(A \beta+=35.2 \%$ for $F R \leq 30$ vs $A \beta+=28.2$ for $F R>30)$ and for $T R$ was 47 $(A \beta+=35.7$ for $T R \leq 47$ and $A \beta+=29.5$ for $T R=48)$. Individuals in SOMI-3 and SOMI-4 stages have higher rates of amyloid positivity $(40.0 \%$ and $43.8 \%$, respectively). While SOMI stage does not eliminate the need for amyloid screening it provides a strategy for increasing the yield of amyloid positives among those receiving biomarker assessment.

These data pertain to a study of an amyloid targeted therapy. For trials that target other pathologic mechanisms (e.g., tau), when data becomes available, we would assess rates of Tau positivity by SOMI stage to optimize a sampling design. However, as indicated by the many failed trials of AD, presence of target pathology (i.e., amyloid) and even successful removal of it from brain (e.g., Aducanumab trials) does not guarantee trial success. Using sensitive clinical tests such as SOMI and PACC, which are proven as effective tests for detecting early and late cognitive decline during the preclinical stages of $A D$, in combination with biomarkers can lead to improved trial design.

A recent study from the Harvard Aging Brain Study (HABS) showed that $A B+C N$ individuals demonstrated longitudinal decline on all individual PACC components and all PACC variations. ${ }^{33}$ Differences between the $A \beta+$ and $A \beta$ - groups emerged earlier when 
FCSRT FR was included in the PACC. FR alone or combined with total recall was the only individual component of the PACC to show differences between the $A \beta+$ group who progressed to CDR 0.5 versus those that remained stable. These findings support the notion that using FSCRT-derived SOMI system can improve our ability to detect early and late cognitive decline during the preclinical stages of $A D$, which may prove advantageous in the prevention trials' design.

In the context of clinical trials, we envision that SOMI could be used as a criteria for prioritizing enrollment of participants. The optimal criteria for sample enrichment based on SOMI depends upon the design of trial, on its duration and on its objectives. One approach could be using SOMI staging for selecting participants who are more likely to be amyloid positive prior to evaluation with expensive or invasive biomarkers such as PET scans or CSF-based biomarkers. SOMI- 3 and 4 groups are more likely to be amyloid positive, however selecting SOMI 3 and 4 individuals for biomarker evaluation has its own drawbacks. While this approach would increase biomarker positivity rate and decrease the cost of biomarker assessment prior to enrollment, it would also require cognitive screening of far more individuals with the FCSRT, which could potentially slow down recruitment and also limit the generalizability of findings to those who are SOMI 3 and 4 at the time of enrollment.

An alternative approach might be to enroll individuals who are SOMI- 1 or greater. While this approach has minimal value in enrichment of sample with amyloid positive individuals prior to obtaining amyloid PET, based on our previous studies, this group is 
expected to show faster cognitive decline and incident dementia in a shorter timeframe, which is more appropriate for trials. ${ }^{21,24}$ In the Einstein Aging Study, we showed that among 142 participants who developed AD over 10 years, average time to diagnosis was seven years if FR was intact $>30$ (SOMI-0), five years for SOMI-1, four years for SOMI-2 and two years for SOMI-3/4. ${ }^{24}$ The trajectory of FR decline in the preclinical AD continuum of the Baltimore Longitudinal Study of Aging (BLSA) participants was consistent with SOMl's prediction. FR declined gradually, beginning at seven years, until there was a doubling of the rate of FR decline approximately four years later. ${ }^{21}$ Based on these results, we expect that in a trial where time-to-dementia is the endpoint, SOMI system would add important information, which could be used to match the characteristics of the eligible sample to the design and the duration of the study. Given the long duration of progression to dementia among the SOMI-0 group, the expected rate of memory decline is likely too slow to demonstrate treatment benefits in any of the current clinical trials.

SOMI system could also inform clinical trial design as an outcome measure. SOMI-3 is highly associated with $A D$ neuropathology defined by current guidelines ${ }^{34}$ and neurofibrillary tangle pathology defined by Braak and Braak. ${ }^{35}$ Compared to participants with no memory impairment (SOMI-0), participants classified into SOMI-3 and -4 stages were four times more likely to have positive AD neuropathology and were nearly six times as likely to have more advanced Braak NFT pathology. Using conversion from earlier stages to SOMI-3 as an outcome in conjunction with biomarkers could be an effective method to reduce the duration of active treatment in the trials. 
It should be noted that we do not believe that the FCSRT is capturing something unique. Other memory tests are also effective at predicting incident $\mathrm{MCl}$ and dementia. ${ }^{36,37}$ However, the ability to distinguish measures of storage and retrieval and the control of cognitive processes may provide particular benefits. Many studies by our group and others indicate that FCSRT is a sensitive cognitive test for detecting signs of memory impairment in both storage and retrieval in prodromal stages of $A D$ and other dementia. ${ }^{15-17,22}$ SOMI staging provides a practical system (and cut-offs for classification) that can be used as part of the design of future interventional studies.

Another approach to identifying persons in the earliest stages of $A D$ includes using at least two tests of a single domain or single tests of multiple domains in addition to specific memory parameters (e.g., learning slope). ${ }^{38,39}$ This approach has theoretical advantages and disadvantages over our approach which relies on a single cognitive test. We expect there to be overlap between early and late $\mathrm{MCl}$ and SOMI stages. These approaches have not been compared head-to-head in terms of simplicity, ease of use and predictive validity for biomarkers or cognitive decline.

There are limitations of this study worth noting. $3.4 \%$ of participants could not be classified into a SOMI stage because their retrieval was impaired, but memory storage was unimpaired. We plan to study characteristics of this unique group in our future studies. In the setting of clinical trials, where screening with the FCSRT precedes biomarker assessment, excluding unclassified participants until we better understand 
them may improve outcomes by decreasing the number of participants who do not display the core clinical memory AD phenotype. The A4 study is a prevention trial and therefore all participants who had PET scans were cognitively normal at baseline. Excluding participants with very high LMDR-Ila criteria (>1.SD) from the A4 trial slightly affects generalizability of our study. However, even after excluding these participants, the sample includes a large range of cognitive abilities among individuals considered normal according to the current gold stand diagnostic criteria. Another limitation is the high educational level of the cohort. We are hoping to follow up this study in a more diverse cohort in the future to confirm its generalizability to other samples.

In this study, we used data from a very large sample of older adults. While using large datasets is generally considered an advantage in epidemiologic studies, it also poses a statistical challenge: In large samples, analysis power is substantially increased. This might lead to an exaggerated tendency to reject the null hypotheses while differences are not clinically or biologically meaningful. However, our results could be considered robust, as they are hypothesis driven and also consistent with literature and prior studies in other samples with diverse population and different sample size. ${ }^{4,6-8,10,17}$ Finally, the relationship between SOMI stage and MRI volumetrics would likely be weaker in a sample not screened for amyloid positivity. Volumetric data is currently available only for the amyloid positive individuals in the A4 study, but a parallel study (LEARN cohort) is following a smaller sample $(\mathrm{N}=600)$ of amyloid negative individuals from A4 study, and we are hoping to conduct a follow up study using data from that sample. 
In conclusion, even in highly selected 'cognitively normal' older adults, presence of ADpathology is closely related to memory impairment based on SOMI stages. We envision that SOMI could be used for enrichment of future clinical trials. 
Supplement -- http://links.lww.com/WNL/B804

\section{REFERENCES}

1. Dubois B, Feldman HH, Jacova $\mathrm{C}$, et al. Advancing research diagnostic criteria for Alzheimer's disease: the IWG-2 criteria. The Lancet Neurology. 2014;13(6):614-629.

2. Dubois B, Epelbaum S, Nyasse F, et al. Cognitive and neuroimaging features and brain beta-amyloidosis in individuals at risk of Alzheimer's disease (INSIGHT-preAD): a longitudinal observational study. Lancet Neurol. 2018;17(4):335-346.

3. Sarazin M, Chauvire V, Gerardin E, et al. The amnestic syndrome of hippocampal type in Alzheimer's Disease: An MRI study. Journal of Alzheimer's Disease. 2010;22:285-294.

4. Hanseeuw BJ, Betensky RA, Jacobs HIL, et al. Association of Amyloid and Tau With Cognition in Preclinical Alzheimer Disease: A Longitudinal Study. JAMA Neurol. 2019;76(8):915-924.

5. Insel PS, Donohue MC, Sperling R, Hansson O, Mattsson-Carlgren N. The A4 study: $\beta$ amyloid and cognition in 4432 cognitively unimpaired adults. Ann Clin Transl Neurol. 2020;7(5):776-785.

6. Xie J, Gabelle A, Dorey A, et al. Initial memory deficit profiles in patients with a cerebrospinal fluid Alzheimer's disease signature. J Alzheimers Dis. 2014;41(4):11091116.

7. Wagner $\mathrm{M}$, Wolf $\mathrm{S}$, Reischies $\mathrm{FM}$, et al. Biomarker validation of a cued recall memory deficit in prodromal Alzheimer disease. Neurology. 2012;78(6):379-386.

8. Slachevsky A, Barraza P, Hornberger M, et al. Neuroanatomical Comparison of the "Word" and "Picture" Versions of the Free and Cued Selective Reminding Test in Alzheimer's Disease. J Alzheimers Dis. 2018;61(2):589-600.

9. Bernard CC. PCC characteristics at rest in 10-year memory decliners. Neurobiology of Aging. 2015;36(10):2812-2820.

10. Zammit AR, Ezzati A, Zimmerman ME, Lipton RB, Lipton ML, Katz MJ. Roles of hippocampal subfields in verbal and visual episodic memory. Behavioural Brain Research SreeTestContent1. 2017;317:157-162.

11. Ezzati A, Katz MJ, Zammit AR, et al. Differential association of left and right hippocampal volumes with verbal episodic and spatial memory in older adults. Neuropsychologia. 2016;93(Pt B):380-385.

12. Derby CA, Burns LC, Wang C, et al. Screening for predementia AD: Time-dependent operating characteristics of episodic memory tests. Neurology. 2013;80(14):1307-1314.

13. Katz MJ, Lipton RB, Hall CB, et al. Age-specific and sex-specific prevalence and incidence of mild cognitive impairment, dementia, and Alzheimer dementia in blacks and whites: a report from the Einstein Aging Study. Alzheimer Disease and Associated Disorders. 2012;26(4):335-343.

14. Sarazin M, Berr C, De Rotrou J, et al. Amnestic syndrome of the medial temporal type identifies prodromal AD: A longitudinal study. Neurology. 2007;69(19):1859-1867. 
15. Di Stefano F, Epelbaum S, Coley N, et al. Prediction of Alzheimer's Disease Dementia: Data from the GuidAge Prevention Trial. J Alzheimers Dis. 2015;48(3):793-804.

16. Lemos R, Maroco J, Simoes MR, Santiago B, Tomas J, Santana I. The free and cued selective reminding test for predicting progression to Alzheimer's disease in patients with mild cognitive impairment: A prospective longitudinal study. I Neuropsychol. 2017;11(1):40-55.

17. Teichmann M, Epelbaum S, Samri D, et al. Free and Cued Selective Reminding Test accuracy for the differential diagnosis of Alzheimer's and neurodegenerative diseases: A large-scale biomarker-characterized monocenter cohort study (ClinAD). Alzheimers Dement. 2017;13(8):913-923.

18. Auriacombe S, Helmer C, Amieva H, Berr C, Dubois B, Dartigues JF. Validity of the free and cued selective reminding test in predicting dementia: the $3 \mathrm{C}$ study. Neurology. 2010;74.

19. Grober E, Buschke H. Genuine memory deficits in dementia. Developmental Neuropsychology. 1987;3(1):13-36.

20. Tulving E. Elements of episodic memory. . New York: Oxford University Press. ; 1983.

21. Grober E, An Y, Lipton RB, Kawas C, Resnick SM. Timing of onset and rate of decline in learning and retention in the pre-dementia phase of Alzheimer's disease. J Int Neuropsychol Soc. 2019;25(7):699-705.

22. Auriacombe SM, Helmer CMDP, Amieva HP, Berr CP, Dubois BM, Dartigues JFMDP. Validity of the Free and Cued Selective Reminding Test in predicting dementia: The $3 C$ Study (e-Pub ahead of print). Neurology. 2010;74(22):1760-1767.

23. Papp KV, Rentz DM, Mormino EC, et al. Cued memory decline in biomarker-defined preclinical Alzheimer disease. Neurology. 2017;88(15):1431-1438.

24. Grober E, Veroff AE, Lipton RB. Temporal unfolding of declining episodic memory on the Free and Cued Selective Reminding Test in the predementia phase of Alzheimer's disease: Implications for clinical trials. Alzheimer's \& dementia (Amsterdam, Netherlands). 2018;10:161-171.

25. Jack CR, Jr., Bennett DA, Blennow K, et al. NIA-AA Research Framework: Toward a biological definition of Alzheimer's disease. Alzheimers Dement. 2018;14(4):535-562.

26. Sperling RA, Donohue MC, Raman R, et al. Association of Factors With Elevated Amyloid Burden in Clinically Normal Older Individuals. JAMA Neurol. 2020;77(6):735-745.

27. Pontecorvo MJ, Arora AK, Devine M, et al. Quantitation of PET signal as an adjunct to visual interpretation of florbetapir imaging. European journal of nuclear medicine and molecular imaging. 2017;44(5):825-837.

28. Johnson KA, Sperling RA, Gidicsin CM, et al. Florbetapir (F18-AV-45) PET to assess amyloid burden in Alzheimer's disease dementia, mild cognitive impairment, and normal aging. Alzheimer's \& Dementia. 2013;9(5):S72-S83.

29. Fischl B. FreeSurfer. Neuroimage. 2012;62(2):774-781.

30. Karas G, Sluimer J, Goekoop R, et al. Amnestic mild cognitive impairment: structural MR imaging findings predictive of conversion to Alzheimer disease. AJNR Am J Neuroradiol. 2008;29(5):944-949. 
31. Tanpitukpongse TP, Mazurowski MA, Ikhena J, Petrella JR. Predictive Utility of Marketed Volumetric Software Tools in Subjects at Risk for Alzheimer Disease: Do Regions Outside the Hippocampus Matter? AJNR Am J Neuroradiol. 2017;38(3):546-552.

32. Grober E, Papp K, Rentz D, et al. Neuroimaging correlates of Stages of Objective Memory Impairment (SOMI) system. Alzheimer's \& dementia (Amsterdam, Netherlands) . 2021; in review

33. Mormino EC, Papp KV, Rentz DM, et al. Early and late change on the preclinical Alzheimer's cognitive composite in clinically normal older individuals with elevated amyloid $\beta$. Alzheimers Dement. 2017;13(9):1004-1012.

34. Hyman BT, Phelps CH, Beach TG, et al. National Institute on Aging-Alzheimer's Association guidelines for the neuropathologic assessment of Alzheimer's disease. Alzheimer's \& Dementia. 2012;8(1):1-13.

35. Braak H, Braak E. Neuropathological stageing of Alzheimer-related changes. Acta Neuropathol. 1991;82.

36. Chang Y-L, Bondi MW, Fennema-Notestine $C$, et al. Brain substrates of learning and retention in mild cognitive impairment diagnosis and progression to Alzheimer's disease. Neuropsychologia. 2010;48(5):1237-1247.

37. Duke Han S, Nguyen CP, Stricker NH, Nation DA. Detectable Neuropsychological Differences in Early Preclinical Alzheimer's Disease: A Meta-Analysis. Neuropsychol Rev. 2017;27(4):305-325.

38. Thomas KR, Edmonds EC, Eppig J, Salmon DP, Bondi MW. Using Neuropsychological Process Scores to Identify Subtle Cognitive Decline and Predict Progression to Mild Cognitive Impairment. J Alzheimers Dis. 2018;64(1):195-204.

39. Thomas KR, Bangen KJ, Weigand AJ, et al. Objective subtle cognitive difficulties predict future amyloid accumulation and neurodegeneration. Neurology. 2020;94(4):e397e406. 
Table 1. Stages of Objective Memory Impairment defined by Free Recall and Total Recall score ranges and years to diagnosis on the picture version of the Free and Cued Selective Reminding Test with Immediate Recall (pFCSRT+IR).

\begin{tabular}{|c|c|c|c|c|}
\hline \multicolumn{2}{|c|}{$\begin{array}{l}\text { Stages of Objective Memory Impairment } \\
\text { (SOMI) }\end{array}$} & Rree & $\begin{array}{l}\text { Total } \\
\text { Recall } \\
\text { Scores }\end{array}$ & Class of Memory Impairment \\
\hline 0 & No Memory Impairment & $>30$ & $>46$ & None detected by pFCSRT+IR \\
\hline 1 & Subtle Retrieval Impairment & $25-30$ & $>46$ & $\begin{array}{l}\text { Free recall declines at a constant } \\
\text { rate. Storage is preserved. }\end{array}$ \\
\hline 2 & Moderate Retrieval Impairment & $20-24$ & $>46$ & $\begin{array}{l}\text { Rate of free recall decline doubles. } \\
\text { Executive dysfunction accelerates. } \\
\text { Storage is preserved. }\end{array}$ \\
\hline 3 & Subtle Storage Impairment & any & $45-46$ & Cuing fails to normalize total recall. \\
\hline 4 & $\begin{array}{l}\text { Significant Storage } \\
\text { Impairment compatible with } \\
\text { dementia }\end{array}$ & any & $33-44$ & $\begin{array}{l}\text { Cognitive decline accelerates } \\
\text { heralding ADL impairment. }\end{array}$ \\
\hline
\end{tabular}

Notes. A subset of participants does not meet the SOMI criteria as summarized in the table (FR<20 and TR $>46$ ). Their retrieval is impaired but storage is unimpaired (RISU). 
Table 2. Sample characteristics.

\begin{tabular}{|c|c|c|c|c|c|c|c|}
\hline & & \multicolumn{6}{|c|}{ SOMI stage } \\
\hline & $\begin{array}{c}\text { All } \\
N=4484\end{array}$ & $\begin{array}{c}0 \\
N=2194\end{array}$ & $\begin{array}{c}1 \\
N=1210\end{array}$ & $\begin{array}{c}2 \\
N=407\end{array}$ & $\begin{array}{c}3 \\
N=463\end{array}$ & $\begin{array}{c}4 \\
N=48\end{array}$ & $\begin{array}{l}\text { RISU } \\
\mathrm{N}=162\end{array}$ \\
\hline Female, $\%$ & 40.6 & 30.6 & 44.5 & 55.3 & 54.2 & 62.5 & 71.6 \\
\hline APOE4 positive, $\%$ & 34.6 & 34.7 & 35.1 & 35.3 & 34.1 & 31.2 & 38.6 \\
\hline$A \beta+, \%$ & 32.3 & 30.0 & 31.0 & 34.9 & 40.0 & 43.8 & 42.5 \\
\hline $\begin{array}{l}\text { Age, years, mean } \\
\text { (SD) }\end{array}$ & $\begin{array}{l}71.3 \\
(4.6)\end{array}$ & $\begin{array}{l}70.4 \\
(4.2)\end{array}$ & $\begin{array}{l}71.5 \\
(4.5)\end{array}$ & $\begin{array}{l}72.9 \\
(4.9)\end{array}$ & $\begin{array}{l}72.3 \\
(5.1)\end{array}$ & $\begin{array}{l}74.1 \\
(6.2)\end{array}$ & $\begin{array}{l}73.5 \\
(5.4)\end{array}$ \\
\hline Education, years (SD) & $\begin{array}{l}16.5 \\
(2.8)\end{array}$ & $\begin{array}{l}16.6 \\
(2.8)\end{array}$ & $\begin{array}{l}16.5 \\
(2.9)\end{array}$ & $\begin{array}{l}16.5 \\
(2.8)\end{array}$ & $\begin{array}{l}16.3 \\
(2.8)\end{array}$ & $\begin{array}{l}15.9 \\
(2.6)\end{array}$ & $\begin{array}{l}16.8 \\
(2.6)\end{array}$ \\
\hline PACC, mean (SD) & $\begin{array}{c}0 \\
(2.5)\end{array}$ & $\begin{array}{c}1.2 \\
(2.1)\end{array}$ & $\begin{array}{l}-0.4 \\
(1.9)\end{array}$ & $\begin{array}{l}-2.1 \\
(2.0)\end{array}$ & $\begin{array}{l}-1.6 \\
(2.4)\end{array}$ & $\begin{array}{l}-3.9 \\
(3.2)\end{array}$ & $\begin{array}{l}-3.1 \\
(1.9)\end{array}$ \\
\hline MMSE, mean (SD) & $\begin{array}{l}28.7 \\
(1.2)\end{array}$ & $\begin{array}{l}28.9 \\
(1.1)\end{array}$ & $\begin{array}{l}28.7 \\
(1.9)\end{array}$ & $\begin{array}{l}28.4 \\
(1.3)\end{array}$ & $\begin{array}{l}28.4 \\
(1.3)\end{array}$ & $\begin{array}{l}27.9 \\
(1.5)\end{array}$ & $\begin{array}{l}28.5 \\
(1.2)\end{array}$ \\
\hline LM-IR, mean (SD) & $\begin{array}{l}12.9 \\
(3.1)\end{array}$ & $\begin{array}{l}13.4 \\
(3.1)\end{array}$ & $\begin{array}{l}12.9 \\
(3.1)\end{array}$ & $\begin{array}{l}12.3 \\
(3.0)\end{array}$ & $\begin{array}{l}12.1 \\
(3.0)\end{array}$ & $\begin{array}{l}10.5 \\
(2.7)\end{array}$ & $\begin{array}{l}11.6 \\
(2.9)\end{array}$ \\
\hline LM-DR, mean (SD) & $\begin{array}{l}11.7 \\
(3.2)\end{array}$ & $\begin{array}{l}12.2 \\
(3.1)\end{array}$ & $\begin{array}{l}11.6 \\
(3.2)\end{array}$ & $\begin{array}{l}10.8 \\
(3.0)\end{array}$ & $\begin{array}{l}10.6 \\
(3.2)\end{array}$ & $\begin{array}{c}8.9 \\
(2.5)\end{array}$ & $\begin{array}{l}10.3 \\
(2.7)\end{array}$ \\
\hline $\begin{array}{l}\text { Digit symbol, mean } \\
\text { (SD) }\end{array}$ & $\begin{array}{l}43.7 \\
(8.9)\end{array}$ & $\begin{array}{l}45.6 \\
(8.7)\end{array}$ & $\begin{array}{l}43.2 \\
(8.6)\end{array}$ & $\begin{array}{l}40.4 \\
(8.5)\end{array}$ & $\begin{array}{l}41.4 \\
(9.0)\end{array}$ & $\begin{array}{l}39.7 \\
(9.3)\end{array}$ & $\begin{array}{l}38.6 \\
(8.4)\end{array}$ \\
\hline GDS, mean (SD) & $\begin{array}{c}1.5 \\
(0.5)\end{array}$ & $\begin{array}{c}1.0 \\
(1.4)\end{array}$ & $\begin{array}{l}1.03 \\
(1.4)\end{array}$ & $\begin{array}{l}1.12 \\
(1.3)\end{array}$ & $\begin{array}{l}1.01 \\
(1.4)\end{array}$ & $\begin{array}{c}1.2 \\
(1.6)\end{array}$ & $\begin{array}{l}1.36 \\
(1.7)\end{array}$ \\
\hline
\end{tabular}

Note. Abbreviations: $A \beta, \beta$-amyloid; RISU, retrieval impaired storage unimpaired; APOEع4, apolipoprotein E $\varepsilon 4$ allele; LR-IR, logical memory immediate recall; LR-DR, logical memory delayed recall; 
MMSE, mini-mental state Exam; GDS, geriatric depression scale. RISU-retrieval impaired storage unimpaired. 
Table 3. Characteristics of sample stratified by amyloid status and SOMI.

\begin{tabular}{|c|c|c|c|c|c|c|c|c|c|c|c|c|}
\hline SOMI stage & \multicolumn{2}{|c|}{0} & \multicolumn{2}{|c|}{1} & \multicolumn{2}{|c|}{2} & \multicolumn{2}{|c|}{3} & \multicolumn{2}{|c|}{4} & \multicolumn{2}{|c|}{ RISU } \\
\hline Amyloid Status & - & + & - & + & - & + & - & + & - & + & - & + \\
\hline N (\%) & $\begin{array}{r}1538 \\
(70.0)\end{array}$ & $\begin{array}{c}658 \\
(30.0)\end{array}$ & $\begin{array}{r}835 \\
(69.0)\end{array}$ & $\begin{array}{c}376 \\
(31.0)\end{array}$ & $\begin{array}{c}265 \\
(65.2)\end{array}$ & $\begin{array}{c}142 \\
(34.9)\end{array}$ & $\begin{array}{c}279 \\
(60.0)\end{array}$ & $\begin{array}{c}186 \\
(40.0)\end{array}$ & $\begin{array}{c}27 \\
(56.3)\end{array}$ & $\begin{array}{c}21 \\
(43.8)\end{array}$ & $\begin{array}{c}93 \\
(57.4)\end{array}$ & $\begin{array}{c}69 \\
(42.6)\end{array}$ \\
\hline Female, $\%$ & 29.2 & 32.1 & 45.4 & 42.6 & 61.1 & 44.4 & 55.9 & 51.6 & 74.1 & 47.6 & 64 & 52 \\
\hline APOE4 positive, $\%$ & 25.1 & 56.4 & 22.4 & 62.5 & 24.5 & 54.2 & 19.7 & 54.3 & 11.1 & 57.1 & 23.7 & 56.5 \\
\hline Age, years, mean (SD) & $\begin{array}{l}70.0 \\
(4.0)\end{array}$ & $\begin{array}{l}71.1 \\
(4.4)\end{array}$ & $\begin{array}{l}71.2 \\
(4.5)\end{array}$ & $\begin{array}{l}72.0 \\
(4.7)\end{array}$ & $\begin{array}{l}72.8 \\
(5.0)\end{array}$ & $\begin{array}{l}73.2 \\
(5.0)\end{array}$ & $\begin{array}{l}71.5 \\
(4.9)\end{array}$ & $\begin{array}{l}73.6 \\
(5.2)\end{array}$ & $\begin{array}{l}73.9 \\
(6.1)\end{array}$ & $\begin{array}{l}74.4 \\
(6.5)\end{array}$ & $\begin{array}{l}74.5 \\
(5.0)\end{array}$ & $\begin{array}{r}72.9 \\
(5.8)\end{array}$ \\
\hline Education, years & $\begin{array}{l}16.6 \\
(2.8)\end{array}$ & $\begin{array}{l}16.6 \\
(2.7)\end{array}$ & $\begin{array}{l}16.6 \\
(2.8)\end{array}$ & $\begin{array}{l}16.5 \\
(3.0)\end{array}$ & $\begin{array}{l}16.6 \\
(2.9)\end{array}$ & $\begin{array}{l}16.6 \\
(2.5)\end{array}$ & $\begin{array}{l}16.2 \\
(2.8)\end{array}$ & $\begin{array}{l}16.6 \\
(2.8)\end{array}$ & $\begin{array}{l}16.3 \\
(2.8)\end{array}$ & $\begin{array}{l}16.6 \\
(2.5)\end{array}$ & $\begin{array}{l}17.1 \\
(2.7)\end{array}$ & $\begin{array}{l}16.6 \\
(2.3)\end{array}$ \\
\hline PACC, mean (SD) & $\begin{array}{c}1.4 \\
(2.1)\end{array}$ & $\begin{array}{c}1.0 \\
(2.1)\end{array}$ & $\begin{array}{l}-0.3 \\
(1.9)\end{array}$ & $\begin{array}{l}-0.5 \\
(2.0)\end{array}$ & $\begin{array}{l}-2.00 \\
(2.0)\end{array}$ & $\begin{array}{l}-2.3 \\
(2.1)\end{array}$ & $\begin{array}{l}-1.4 \\
(2.3)\end{array}$ & $\begin{array}{l}-1.9 \\
(2.5)\end{array}$ & $\begin{array}{l}-3.1 \\
(3.3)\end{array}$ & $\begin{array}{l}-3.0 \\
(2.7)\end{array}$ & $\begin{array}{l}-3.4 \\
(2.2)\end{array}$ & $\begin{array}{l}-2.9 \\
(2.2)\end{array}$ \\
\hline
\end{tabular}

Note. Abbreviations: A $\beta, \quad \beta$-amyloid; RISU, retrieval impaired storage unimpaired; APOE\&4, apolipoprotein E \&4 allele. 
Figure 1. Box plot comparing Amyloid PET SUVR across different SOMI subgroups for the whole population (a) and sample stratified based on amyloid status (b). Groups significantly different from each other are connected to each other with brackets $(*=p<0.05 ; * *=p<0.001)$.
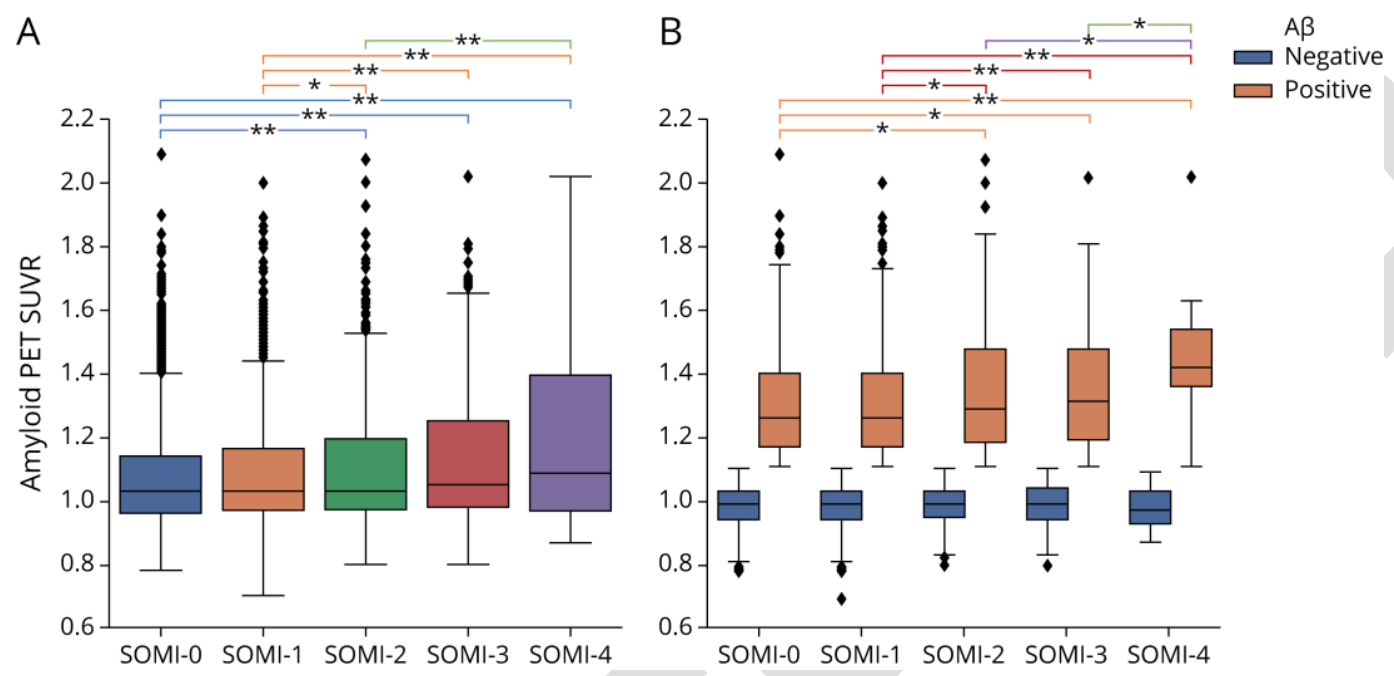
Figure 2. Volume of different regions by SOMI stage. Volumetric measures are normalized and rescaled to $0-1$ to improve comparability. Groups significantly different from each other $(p<0.05)$ are connected to each other with lines.
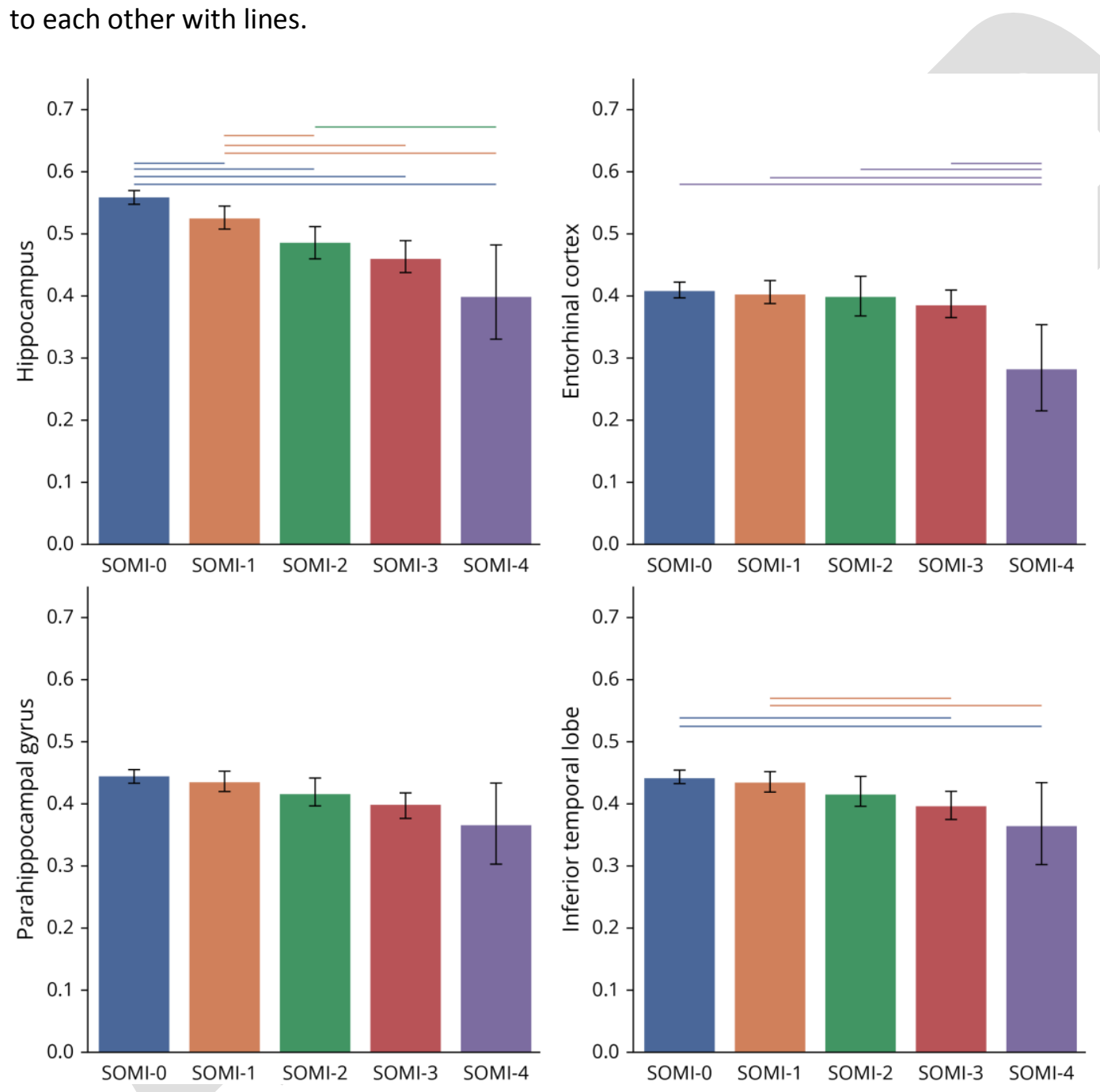


\title{
Neurology
}

\author{
Associations of Stages of Objective Memory Impairment (SOMI) with Amyloid PET and \\ Structural MRI: The A4 Study \\ Ellen Grober, Richard B. Lipton, Reisa A. Sperling, et al. \\ Neurology published online February 23, 2022 \\ DOI 10.1212/WNL.0000000000200046
}

\section{This information is current as of February 23, 2022}

Updated Information \&

Services

Subspecialty Collections

Permissions \& Licensing

Reprints including high resolution figures, can be found at:

http://n.neurology.org/content/early/2022/02/23/WNL.0000000000200046.f ull

This article, along with others on similar topics, appears in the following collection(s):

Alzheimer's disease

http://n.neurology.org/cgi/collection/alzheimers_disease

Class I

http://n.neurology.org/cgi/collection/class_1

Memory

http://n.neurology.org/cgi/collection/memory

MRI

http://n.neurology.org/cgi/collection/mri

PET

http://n.neurology.org/cgi/collection/pet

Information about reproducing this article in parts (figures,tables) or in its entirety can be found online at:

http://www.neurology.org/about/about_the_journal\#permissions

Information about ordering reprints can be found online:

http://n.neurology.org/subscribers/advertise

Neurology ® is the official journal of the American Academy of Neurology. Published continuously since 1951, it is now a weekly with 48 issues per year. Copyright Copyright (C) 2022 The Author(s). Published by Wolters

Kluwer Health, Inc. on behalf of the American Academy of Neurology.. All rights reserved. Print ISSN:

0028-3878. Online ISSN: 1526-632X.

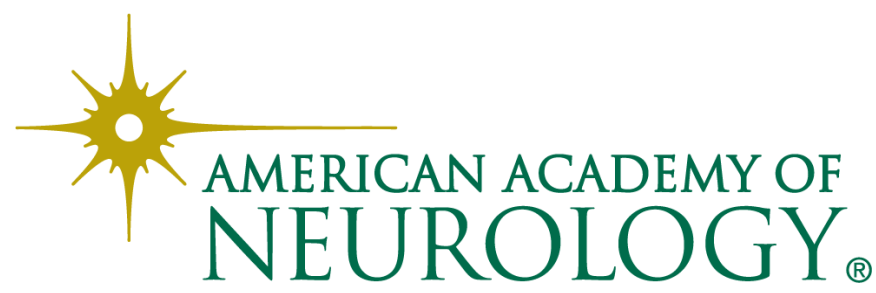

